\title{
LA CRÍTICA DE LA ECONOMÍA \\ DE MERCADO EN KARL POLANYI: \\ EL ANÁLISIS INSTITUCIONAL COMO \\ PENSAMIENTO PARA LA ACCIÓN
}

\author{
Arturo Lahera Sánchez \\ Universidad Complutense de Madrid \\ E-mail: soso1z8@emducms1.sis.ucm.es
}

\begin{abstract}
RESUMEN
La obra de Karl Polanyi supone una de las perspectivas más apasionantes para abordar los fenómenos económicos. Polanyi realizará una crítica epistemológica y ontológica a los fundamentos del pensamiento económico clásico y neoclásico a partir de la alternativa de su análisis institucional, que pretende incrustar los actos económicos en la matriz cultural, política y social en que se producen, con lo que la economía es conformada históricamente por la totalidad social en que se inscribe. A partir de todo esto, rastreará la construcción histórica de la economía de mercado como un inmenso y violento proceso social artificial, que no obedeció a supuestas características de la naturaleza humana, sino a una apuesta ideológica, axiológica y política radicalmente diferente a las formas anteriores en que los grupos humanos habían organizado e integrado los recursos materiales y su sustento. Su crítica teórica a la economía de mercado como desintegradora de la esencia humana de la sociedad implica necesariamente una acción política transformadora y reguladora del mercado, articulando sus reflexiones como un pensamiento para la acción.
\end{abstract}

"- Nunca debes imaginarte nada! De eso precisamente se trata. No debes dejarte llevar de la imaginación. Guiate en todas las circunstancias y gobiérnate por lo real. No está lejano el día en que tengamos un cuerpo de gobernantes imbuidos de realismo y ese Gobierno estará integrado por jefes de negociado, realistas, que obligarán a las gentes a vivir de acuerdo con la realidad y descartando cuanto no sea realidad. Tenéis que suprimir por completo la palabra imaginación. La imaginación no sirve para nada en la vida. (...)"

\section{Reis}


"- "La sala de esta escuela es una ciudad inmensa en la que vive un millón de habitantes, $y$ de ese millón de habitantes, solamente se mueren de hambre en la calle, al año veinticinco. ¿Qué os parece esta prosperidad?". Lo mejor que se me ocurrió contestarle fue que para los que se morían de hambre era lo mismo que la ciudad tuviese un millón que un millón de millones de habitantes. Y también en esto me equivoqué.»

(Charles Dickens, Tiempos dificiles.)

\section{PRESENTACIÓN}

La obra de Karl Polanyi permite acceder a los fenómenos económicos desde una perspectiva y una mirada crítica que supone una de las contribuciones más apasionantes a las ciencias de la cultura y a la sociología económica. El hilo conductor de su reflexión se centrará en rastrear el origen sociohistórico y cultural de la economía de mercado mediante su comparación crítica con las formas en que otras sociedades históricas han organizado las esferas de la producción, distribución y consumo de bienes y servicios. Esta comparación exhaustiva y compleja le permitirá establecer no sólo las características de la economía de mercado, sino fundamentalmente la forma en que ésta transformó las relaciones sociales sobre las que se organiza la sociedad. Al mismo tiempo, este objetivo pasará ineludiblemente por realizar una crítica del pensamiento económico tanto en sus aspectos disciplinares como respecto a sus concepciones sobre la naturaleza del ser humano y la sociedad.

El objeto de análisis de la reflexión contenida en este artículo se centra en presentar e interpretar el marco teórico y metodológico que Polanyi construirá para explicar y comprender la aparición histórica de la economía de mercado. Primeramente, se realizará un estudio del esquema conceptual de este autor reflejado en el análisis institucional como herramienta epistemológica de crítica al análisis económico clásico y neoclásico. A continuación, se conectarán esos componentes de su análisis institucional con la visión antropológica que Polanyi desarrolla sobre el ser humano, caracterizada por inscribir las prácticas sociales de los sujetos dentro de procesos culturales de socialización y acuñación de comportamientos, todo ello en relación a la forma en que las diferentes sociedades históricas organizan la provisión colectiva del sustento humano. Una vez establecido el aparato conceptual del análisis institucional polanyiano, se presentarán los sistemas axiológicos en que se sostienen tanto el análisis económico criticado por Polanyi como su alternativa institucional, que se empleará seguidamente para rastrear histórica y culturalmente los procesos sociales de movilización e inversión de recursos que permitieron la construcción de la economía y la sociedad de mercado.

Por último, se concluirá esta reflexión recuperando el carácter transformador y político de la obra de Karl Polanyi, ya que tanto su edificio teórico y conceptual, analizado a lo largo de este texto, como sus estudios empíricos 
sobre las sociedades y economías del pasado tan sólo tienen sentido si se consideran como apuestas para construir una nueva forma de integrar la sociedad y su sustento al margen del mercado como institución, con lo que se defenderá en este artículo la necesidad de considerar las aportaciones de este autor heterodoxo no exclusivamente como una contribución intelectual y académica, sino también como un llamamiento desesperado a la movilización política para transformar la realidad: su obra supone esencialmente un pensamiento para la acción transformadora.

\section{LA CRÍTICA AL ANÁLISIS ECONÓMICO: LA ALTERNATIVA DEL ANÁLISIS INSTITUCIONAL}

La obra de Karl Polanyi se centrará en resolver el problema del lugar que ocupa la economía en la sociedad (Polanyi, 1994: 59) ${ }^{1}$ y el desplazamiento que la esfera de los fenómenos económicos ha sufrido dentro de las matrices de relaciones sociales y culturales que han configurado las diferentes sociedades históricas.

Ahora bien, Polanyi tiene presente en la formulación de este problema el sistema económico de mercado como fenómeno social a explicar, lo que implica rastrear la constitución de un orden social basado en mercados autorregulados y formadores de precios fluctuantes como piedra de toque de la economía. Surge así la pregunta de "cómo, cuándo y dónde nacieron el comercio de mercado, los precios fluctuantes, las cuentas de ganancias, los métodos de mercado y todas las características de una economía organizada en torno al mercado» (Polanyi, 1976a: 75). Esto lleva, asimismo, a explicar la plausibilidad de los presupuestos que aparecen en el análisis económico construido por la teoría económica clásica y neoclásica ${ }^{2}$ para analizar y caracterizar la economía de mercado de nuestro tiempo, así como si esos presupuestos pueden ser aplicables a las diferentes formas de organizar la economía en el pasado. Esta economía de mercado estaría fundada en la socialización de una mentalidad capitalista dedicada a obtener ganancias mediante la maximización del beneficio obtenido en el intercambio de todo tipo de mercancías y servicios (incluyendo el trabajo y la tierra) a través de un gran mercado único autorregulado mediante precios fluctuantes: supone, por tanto, una conducta economizadora y la creación de precios a partir de la relación oferta-demanda como controladora de la producción (Polanyi, Arensberg y Pearson, 1976: 47; Polanyi, 1976a: 65; ESH: 78-82, 217).

Para conseguir establecer y desvelar cuáles han sido los lugares ocupados

${ }^{1}$ Esta obra es El sustento del hombre; a partir de ahora aparecerá mencionada en este texto como ESH.

${ }^{2}$ Los desarrollos teóricos de la ciencia económica clásica y neoclásica serán denominados a lo largo de todo el texto exclusivamente como análisis económico. 
por la vida económica en la sociedad, Polanyi parte de considerar que la economía de mercado, tanto en su formulación teórica como en su realidad empírica, no es más que un fenómeno histórico único y específico dentro de la historia de la humanidad (Dalton, 1968: xii).

Esta premisa es el eje a partir del cual Polanyi articulará, por un lado, una crítica epistemológica y ontológica a las teorías que estructuran el análisis económico para explicar el comportamiento económico de los individuos en la sociedad y, por otro lado, una crítica política a la forma en que la economía de mercado organiza el tejido social, todo ello para establecer alternativas políticas para reconfigurar y transformar ese orden social de mercado. Sin embargo, sería necesario enfatizar que ambos momentos críticos están íntimamente ligados, puesto que la crítica teórica sólo tiene sentido en la búsqueda de una plasmación práctica o pragmática de sus presupuestos mediante el establecimiento de un pensamiento para la acción sobre la realidad ${ }^{3}$.

En la resolución de este problema, Polanyi se interrogará sobre la fiabilidad del análisis económico para analizar la economía del pasado y del presente (Pearson, en ESH: 42), y sobre si sus conceptos teóricos basados en la institución del mercado son aplicables a todo tipo de sociedad y, sobre todo, a aquellas sociedades históricas sin mercado (ESH: 55).

\subsection{La falacia económica del análisis económico: economia formal versu economía sustantiva}

Para Polanyi, el análisis económico se basa en una "falacia económica» que iguala la economía general humana a lo largo de la historia con una economía organizada alrededor de la institución del mercado, concretada en el mecanismo "oferta-demanda-precios fluctuantes» como forma de adquisición de bienes y servicios de reproducción individual y social: «reducir la esfera del género económico a los fenómenos del mercado es borrar de la escena la mayor parte de la historia del hombre. Por otro lado, ampliar el concepto de mercado a todos los fenómenos económicos es atribuir artificialmente a todas las cuestiones económicas las características particulares que acompañan al fenómeno del mercado» (ESH: 78).

Para desconstruir esta falacia, Polanyi elaborará una serie de conceptos teóricos alternativos, unas herramientas conceptuales de análisis (Polanyi, 1968b), que permitan comprender la existencia de formas de organizar la economía y la sociedad de manera esencialmente distinta a la economía de mercado, es decir, de formas sociales alternativas de construir el orden social.

Para ello, distinguirá entre «economía sustantiva» y «economía formal»:

${ }^{3}$ Como veremos, éste es el origen del propio proceso de construcción e imposición de la propia economía de mercado. 
- El significado o definición sustantiva (real) de la economía supone que los seres humanos requieren un entorno físico que les sustente, siendo dependientes de la naturaleza y del resto de seres humanos para lograr su sustento y su reproducción a través de una interacción institucionalizada. Desde esta perspectiva, la economía es el proceso por el que se obtienen medios de sustento para satisfacer las necesidades materiales (y de integración social) (ESH: 91-92; Polanyi, 1976c: 289-291).

- El significado formal del término "económico» depende de la relación lógica que se establece entre medios y fines para la adquisición de sustento, que es a su vez dependiente de la noción de "ahorrar» o «economizar». Este significado expresa términos de escasez respecto a los medios de subsistencia, lo que implica la necesidad de obtención del máximo resultado en el empleo de esos medios escasos para obtener el sustento, es decir, en su maximización. Este contenido teórico (y las prácticas socializadas a que dará lugar) es la base de la acción racional en la que la escasez hace necesaria la elección; de ahí que en el sistema de la economía de mercado las elecciones individuales se regulen por precios fluctuantes que reflejarán la asignación de recursos escasos, todo lo cual es el objeto del análisis económico. Esa escasez supone la existencia de medios insuficientes para la subsistencia y la competencia de los seres humanos por esos medios (ESH: 92-93; Polanyi, 1976c: 291-293). Para Polanyi, esta concepción sobre la que se basa la economía de mercado postula la insuficiencia de todas las cosas materiales y, por tanto, la competencia entre los seres humanos por la subsistencia, dando lugar «a la creencia universal de que no había suficiente para todos» (ESH: 101).

Ahora bien, para Polanyi, el significado formal de la economía sólo es característico de la economía de mercado como forma de organizar la adquisición del sustento, con lo que sus contenidos sólo son aplicables a ésta y no a las diferentes formas históricas en que las sociedades han organizado real o sustantivamente la esfera económica. Sin embargo, Polanyi advierte que en la alternativa de construcción del orden social establecida por la economía de mercado los significados sustantivos y formal han sido fundidos en la realidad, organizando las actividades del sustento humano a partir de las normas de elección y competencia entre seres humanos (Polanyi, 1976c: 290): en otras palabras, la economía formal se desarrolla realmente al convertirse en economía sustantiva, coincidiendo ambos significados en las prácticas sociales.

Es precisamente esta fusión la que impide conocer cuál ha sido el lugar de la economía en la historia de las diferentes sociedades en las que han existido gran variedad de instituciones diferentes de los mercados en las que estaba integrada la actividad económica del sustento y que, por tanto, no pueden ser explicadas por un conjunto de conceptos analíticos que se ajustan tan sólo a la economía de mercado ${ }^{4}$, es decir, no pueden ser explicadas por el significado

4 «Inútil plantear cuestiones que provienen de una economía diferente, organizada de forma diferente» (Foucault, 1972: 164): sus elementos sólo adquieren sentido en el sistema en que 
formal de lo económico, pero sí por el sustantivo, que permitiría conocer cómo se organizaba realmente el sustento sin elementos de mercado y acción racional's.

Cabe destacar que esta distinción conceptual establecida por Polanyi tiene no sólo implicaciones metodológicas en el estudio e investigación de las esferas económicas que no sean o no hayan sido organizadas exclusivamente por la institución del mercado, sino que en términos políticos supone demostrar que las relaciones sociales establecidas por la economía de mercado son tan sólo una opción histórica para la construcción del orden y la sociabilidad humana, y que por tanto han existido y podrían existir formas alternativas de organización social. Por todo ello, la falacia económica denunciada epistemológicamente por Polanyi supone también una "falacia política" al ocultar en el pasado formas de integrar a los individuos al margen de la economía de mercado para la satisfacción de sus necesidades, abriendo el campo de la discusión política al planteamiento de un orden social que permita la obtención del sustento de forma diferente: "políticamente, la historia debería darnos respuestas para resolver algunos de los problemas morales y prácticos más candentes de nuestra época» (ESH: 55).

A partir de todo esto, la obra de Polanyi intentará rastrear cómo se ha producido el desplazamiento de la economía en la sociedad de manera que el significado formal de lo económico haya acabado siendo la forma real o sustantiva en que los seres humanos adquieren el sustento; en definitiva, cuál ha sido y cómo se ha desarrollado la forma en que se ha construido la economía de mercado $^{6}$.

\subsection{El análisis institucional: las formas de integración y la acuñación del comportamiento social}

Para lograr este propósito, Polanyi retomará y desarrollará perspectivas teóricas y metodológicas centradas en considerar y abordar la economía como una

toman su positividad; una reflexión sobre la economía de mercado (su moneda, el comercio y el intercambio) está ligada a unas prácticas y unas instituciones concretas (Foucault, 1972: 166).

5 Sin embargo, la realidad empírica en un sistema de mercado tiende a hacer a los individuos, mediante su socialización, economizadores (Pearson, en ESH: 42): el «economizar» aparece así como un tipo especial de comportamiento institucionalizado. Asimismo, existen múltiples instituciones, relaciones y pautas de comportamiento que no están comprendidas en el economizar, aunque tienen que ver con la forma en que la sociedad produce, distribuye y consume los bienes y servicios (Kaplan, 1976: 229), que requieren ser explicados desde perspectivas diferentes al análisis económico (aunque éste pretende su explicación subsumiéndolos en la lógica de la acción racional).

${ }^{6}$ Cabe destacar que Polanyi afirma que la mentalidad de mercado socializada e institucionalizada en nuestras sociedades supone un obstáculo epistemológico a superar (ESH: 77), ya que el mercado nos resulta muy familiar (Polanyi, Arensberg y Pearson, 1976: 47) y dificulta nuestra comprensión de posibilidades diferentes de organizar la sociedad y su sustento. 
actividad institucionalizada a través de la cual se satisfacen las necesidades materiales de los individuos en sociedad. En esta actividad aparecen las interacciones con el medio físico y las interacciones humanas, pero lo fundamental es que todas ellas están reguladas a partir de una serie de principios de actuación creados culturalmente y que dan lugar a un conjunto de prácticas socializadas en relación a las instituciones sociales que las modelan, por las cuales los seres humanos trabajan, disponen de sus posesiones y realizan actividades en un proceso para la supervivencia (ESH: 104). Este proceso en busca del sustento, y por tanto económico, no tiene una existencia independiente del tejido ecológico, tecnológico y social de su contexto histórico, sino que depende de una situación espacio-temporal conformada por una serie de estructuras institucionales que le dan sentido, y ordenan y organizan las acciones de los individuos (ESH: 106). Por tanto, para comprender las diversas formas históricas en que se ha organizado la esfera económica, incluyendo la economía de mercado $^{7}$, se debe localizar el origen social de los derechos y obligaciones que sancionan los movimientos de mercancías y personas en el proceso económico o, lo que es lo mismo, el uso productivo y distributivo de personas y cosas (Pearson, en ESH: 47-49). Para Polanyi, «las propiedades de unidad y estabilidad, estructura y función, historia y política, confluyen en la economía a través de su investidura institucional» (ESH: 106).

El estudio (y la transformación) de la actividad económica y de la sociedad desde la perspectiva polanyiana del análisis institucional «exige tratar con la totalidad de los aspectos sociales, culturales y psicológicos de la comunidad, pues hasta tal punto están entrelazados que es imposible comprender uno de ellos sin tener en consideración todos los demás» (Malinowski, 1986: 14). De ahí que todo científico social «que se proponga estudiar sólo religión, o bien tecnología u organización social, por separado delimita el campo de su investigación de forma artificial y eso le supondrá una seria desventaja en el trabajo» (Malinowski, 1986: 28) ${ }^{8}$. Es necesario relacionar el proceso económico con las esferas culturales y políticas de la sociedad, puesto que tan sólo adquiere sentido dentro de esas matrices culturales (ESH: 109). Polanyi recoge así las perspectivas o formas de mirar la sociedad de la antropología cultural de Boas, Malinowski o Thurnwald, cuyo enfoque destacaba que la producción y distribución del sustento está incrustada o embebida en relaciones sociales en las que no existía una red de instituciones económicas separadas (ESH: 126). Para Polanyi, será precisamente la separación institucional del sistema económico respecto al resto de la sociedad lo que caracterice a la economía de mercado?.

El proceso económico se situaría así en una forma o configuración social concreta, en un contexto de estructuras sociales que constituyen su semántica y unidad (Godelier, en Polanyi, Arensberg y Pearson, 1976: 16).

8 Sobre el carácter interdisciplinar en que se basa esta perspectiva metodológica, Lahera (1998).

9 En unas notas y apuntes distribuidos a los alumnos de sus cursos sobre historia económica (1947), Polanyi analizará las teorías económicas de diversos autores caracterizándoles como per- 
Sin embargo, ésta sigue siendo consecuencia de la institucionalización de un modo concreto para organizar la economía y la sociedad. El análisis institucional permite así recuperar los procesos de su constitución y mantenimiento al considerar al mercado como una institución organizadora del trabajo, la producción y el consumo: una forma institucional de obtener el sustento humano.

A partir de todo esto, para Polanyi, la actividad económica debe su existencia a una interacción de características culturales (ESH: 62), siendo dependiente de estructuras institucionales definidas (Polanyi, 1968b). Estas estructuras tienen como finalidad el sustento de la sociedad a través del mantenimiento de ésta en términos de integración y cohesión social. Por ello clasificará empíricamente las economías reales históricas como "formas de integración». De esta manera, «las formas de integración designan los movimientos institucionalizados a través de los cuales se conectan los elementos del proceso económico, desde los recursos materiales y el trabajo hasta el transporte, almacenamiento y distribución y mercancías» (ESH: 109): los movimientos de los bienes y las actividades de las personas están institucionalizados o mediados socialmente, requiriendo estructuras institucionales definidas (ESH: 111).

Polanyi distinguirá como principales formas empíricas de integración de la economía humana (ESH: cap. 3; Polanyi, 1976c: 296-302):

- La reciprocidad: describe el movimiento de bienes y servicios entre puntos de un agrupamiento simétrico que se corresponden y cuyos miembros actúan en los asuntos económicos de forma similar en ambas direcciones (por ejemplo, los habitantes de las islas Trobriand o los bánaro de Nueva Guinea).

- La redistribución: representa un movimiento de los medios de sustento hacia un centro y posteriormente desde éste hacia fuera; de ahí que la organización central redistribuidora sea fundamental en la organización social (Dahomey [Polanyi, 1966] o las instituciones redistribuidoras del Estado de Bienestar).

- El intercambio: se produce un movimiento de bienes y servicios entre dos puntos dispersos o fortuitos del sistema. El intercambio requiere la presencia de la institución del mercado, en el que el movimiento bidireccional de bienes entre personas se basa en la obtención del máximo beneficio a partir de la relación oferta-demanda, creando precios fluctuantes para la integración de las actividades económicas de la sociedad (el máximo exponente será la sociedad de mercado occidental del siglo XIX) ${ }^{10}$.

tenecientes a un enfoque societal, interpretando la «economía» como la provisión de bienes materiales de sustento dentro de la totalidad social, o bien a un enfoque economicista, que interpreta la "economía» como el impulso de obtención de ganancia en el que el sistema económico es una esfera institucional separada de la sociedad; estos apuntes están recogidos en Dalton (1968: 120-138).

${ }_{10}$ Aparece también la forma de integración de la hacienda basada en la producción para uso propio de un grupo autárquico (Polanyi, 1968b: 308-309; Polanyi, 1989; Prieto, 1996: 25). 
A partir de la clasificación conceptual sobre las diferentes formas de integración sobre las que se organiza la sociedad y su sustento, uno de los elementos fundamentales del análisis institucional de Polanyi se centra en relacionar las estructuras institucionales que dan lugar a una forma de integración con las actividades y comportamientos de los individuos de una sociedad. Para su perspectiva institucionalista, son precisamente las instituciones culturales de integración las que acuñan los comportamientos de los individuos, con los que éstos no obedecen a tendencias innatas o naturales ${ }^{11}$, sino que surgen de la socialización de prácticas basadas en acciones colectivas $y$ no individuales en situaciones estructuradas a partir de procesos culturales de construcción de estructuras de apoyo que modelan los comportamientos de los miembros de la sociedad: «la estructura de la sociedad está incrustada en el más escurridizo de los materiales: el ser humano» (Malinowski, 1986: 29). Por todo ello, todas las actividades de la sociedad dependen de cómo se construyen y orientan las motivaciones de los individuos ${ }^{12}$, las cuales sólo tienen sentido dentro de la matriz institucional y de relaciones sociales en que se integran, dentro de las unidades semánticas del contexto social. Polanyi destacará que «los meros agregados de conductas personales no bastan para producir las estructuras» (Polanyi, 1957c: 297); de ahí que las conductas individuales dependan de la existencia de determinadas condiciones institucionales que apoyen y socialicen esas conductas: «las actitudes personales individuales no consiguen tener efectos sociales en ausencia de las condiciones sociales necesarias» (ESH: 112) ${ }^{13}$.

Ahora bien, cabe destacar que las formas de integración no suponen etapas necesarias de desarrollo en un orden o sucesión respecto a una supuesta evolución de la humanidad, sino que, por el contrario, pueden aparecer en una misma sociedad histórica (ESH: 116-117; Polanyi, 1968b: 308; Polanyi, 1976c: 301). Por tanto, no son partes fragmentadas de un desenvolvimiento único y progresivo hacia un fin necesario, sino diversas discontinuidades y direcciones. Lo que constituye la originalidad de todas ellas es el modo particular de resolver problemas, que son aproximadamente los mismos para todas las sociedades (Lévi-Strauss, 1995: 304-339), a partir de unos valores culturales específicos. Respecto a la economía de mercado, Polanyi rechaza su aparición exclusiva en la economía occidental del siglo XIX, al haber jugado un papel significativo en la integración de la economía en otras sociedades, aunque sin tener un carácter dominante o hegemónico, tan sólo complementario (ESH: 117). De ahí que elementos de la modernidad (en términos weberianos) como la contabilidad y el beneficio aparezcan también en épocas premodernas: «las semillas de muchos factores que asociamos con el surgimiento de occidente se sembraron en otros lugares diferentes de la Europa occidental» (Goody, 1990).

${ }_{11}$ Como, por ejemplo, un comportamiento natural hacia el trueque y la búsqueda de beneficio defendido por el análisis económico.

12 Para lograr el comportamiento esperado de sus miembros, una sociedad establece instituciones capaces de promover y forzar ese comportamiento, forzando a la naturaleza humana a reflejar ese ideal (Polanyi, 1947: 114).

13 Aparece así la complejidad contextual en que se desarrollan las relaciones sociales de un grupo humano, en la que tan sólo la consideración de la forma en que ese contexto cultural ha sido construido históricamente permite entender las interacciones de los individuos. Aparece así la noción de "configuración social», es decir, "la estructura de interdependencias culturales que vinculan a los individuos mutuamente y que es accesible a la investigación empírica; de esta 
Este enfoque se contrapone así al elaborado por el individualismo metodológico del análisis económico centrado en suponer que la organización social es el resultado espontáneo de las interacciones entre los individuos, que dan lugar al crecimiento también espontáneo de estructuras sociales ordenadas en un proceso evolutivo del que el exponente final y más evolucionado sería la propia economía de mercado (Hayek, 1995: 82-85). Por el contrario, para el análisis institucional no existe tal espontaneísmo, sino procesos históricos de construcción social de instituciones con un determinado contenido axiológico que ha dado lugar al diseño e inversión en estructuras de apoyo (tanto materiales e ideológicas como de conocimiento) para la socialización de prácticas en los individuos, en los que esas instituciones y los valores en que se basan quedan encarnados. Por todo ello, Polanyi se acerca a la economía de mercado (al igual que al resto de sistemas económicos) reconstruyendo los procesos culturales y materiales que llevaron a su surgimiento como consecuencia de su construcción deliberada (Hayek, 1995: 84) ${ }^{14}$.

Por tanto, es necesario explicar el origen de las instituciones y las prácticas socializadas por ellas para comprender el comportamiento de los individuos, que al aparecer inmersos en un contexto de relaciones culturales y sociales están sujetados (de ahí que sean «sujetos») a esa configuración social contextual. Por todo ello, las diferentes formas de integración no sólo dan lugar a la movilización, producción y consumo de bienes, sino que son también productoras de sujetos al quedar acuñados en éstos los comportamientos basados en los valores contenidos en las instituciones que regulan la organización del orden social ${ }^{15}$.

manera, se puede comprobar o reconstruir el campo de decisiones y actuaciones de un individuo concreto dentro de sus cadenas de interdependencias y de su autonomía, así como aproximarse a su explicación» (Elias, 1982: 47-49).

${ }_{14}$ Precisamente Hayek rechazará esta visión, que denomina "constructivismo racionalista", que pretende defender la posibilidad de transformar la realidad a partir de proyectos basados en el designio o diseño humano y que irían en contra del orden espontáneo y evolutivo de las instituciones, cuyo más perfecto exponente será el producido por el mercado, «que hace prósperas a las naciones» (Hayek, 1995: 90). Se opone así a la idea de que se pueda construir una estructura social concebida por los hombres e impuesta a través del cambio en las instituciones. Lo interesante es ver cómo Hayek afirma que el surgimiento de la economía de mercado es resultado no intencional y espontáneo de las interacciones individuales, mientras Polanyi demostrará precisamente que aquélla es resultado de un amplio y violento proceso de construcción deliberada de sus instituciones, de un proceso político de movilización de recursos materiales y simbólicos que encaja perfectamente en ese constructivismo racionalista denostado tanto por Hayek y el individualismo metodológico del análisis económico: la institución del mercado en ninguna parte se ha creado por el mero azar de los actos de intercambio (Kaplan, 1976: 215). Para Hayek, el mercado es básicamente una estructura informacional de asignación de recursos, en la que desaparecen sus estructuras institucionales (Hayek, 1994).

${ }^{15} \mathrm{La}$ consideración de las matrices culturales e institucionales en que se desarrollan las actividades económicas y el comportamiento de los individuos conduce a considerar estos fenómenos como "actos sociales totales». Esto implica que se deba relacionar lo social con lo individual, puesto que ambos son sólo reales en cuanto a que se encuentran integrados en un sistema que les da sentido. La estructura social impone al individuo unos usos y actividades determinados a tra- 
En definitiva, a partir de todas estas construcciones teóricas que enmarcan y definen el análisis institucional, Polanyi pretenderá dar respuesta al surgimiento de la economía de mercado, analizando el proceso histórico de su constitución, para lo cual será necesario recuperar el origen de los valores culturales que fundamentan la institución del mercado y cómo se reflejan en los sujetos y en las estructuras que apoyan su construcción. Asimismo, la comprensión y desvelamiento de este proceso cultural permitiría considerar las posibles alternativas históricas y políticas a la forma de organizar la sociedad a partir del mercado.

\section{ESTRUCTURAS DE PENSAMIENTO: SISTEMAS AXIOLÓGICOS Y CULTURALES DE CONSTRUCCIÓN DEL ORDEN SOCIAL}

La economía de mercado, en tanto que forma de integración o configuración social, está basada en unos principios de organización social determinados, en principios culturales, políticos y económicos que crean orden en la sociedad (Pearson, en ESH: 51). Estos principios se articulan en estructuras de pensamiento que dan sentido a una determinada visión sobre los caracteres de los seres humanos y sus relaciones o interacciones. Para comprender la formación histórica de la economía de mercado es necesario conocer la estructura de pensamiento y los valores en que se basa la institución del mercado, que impone una determinada estructuración de la sociedad (Prieto, 1996: 24). Esta estructura de pensamiento queda recogida en la noción del homo economicus defendida por el individualismo del análisis económico.

\subsection{El individualismo: el homo economicus como individuo del mercado}

El hombre recreado por el análisis económico y, por tanto, el modelo de comportamiento en una economía de mercado está referido a la estructura axiológica del individualismo. Aparece así la valoración de un ser humano individual, libre e igual a los demás humanos, pero cuyo valor social general es que subordina las necesidades de la sociedad a sus propias necesidades (Dumont, 1982: 15). Esta visión supondrá una revolución moderna de los valores y de la ideología común de una sociedad, en este caso la sociedad ordenada a través de la institución del mercado. El sujeto así privilegiado, tanto en la teoría como en la realidad, es un individuo independiente y autónomo, es

vés de sus instituciones (jurídicas, económicas, religiosas...) en un contexto histórico determinado. Por tanto, es necesario observar el comportamiento del individuo enmarcado y acuñado en la totalidad social para averiguar su sentido: «un estudio de lo concreto que es por lo mismo lo completo" (Mauss, 1979). 
decir, no social, que pretende separarse de las limitaciones del tejido social (Dumont, 1982: 18-19). De esta forma, este individuo está separado de sus relaciones sociales, es un ser aislado que, sin embargo, forma parte de un orden natural de las cosas y cuyo eje vital se centrará en la satisfacción de sus deseos ilimitados (Bilbao, 1996: 79).

Este individuo es una realidad natural que posee unas características inmanentes a su propia naturaleza. La naturaleza del individuo de esta estructura de pensamiento individualista se especifica en su tendencia innata al intercambio, al trueque para la satisfacción de esos deseos ilimitados ${ }^{16}$. Surge así un individuo egoísta que se mueve por las determinaciones internas del deseo, que debe vencer cualquier límite que se oponga a su consecución. Para la perspectiva individualista, la libertad humana consiste en actuar de acuerdo con esa naturaleza egoísta (Schopenhauer, 1993; Bilbao, 1996: 80-81), que separa lo que sucede al individuo de la totalidad social en que se inscribe. Su único fin natural es la adquisición ilimitada o indeterminada de bienes por satisfacer un deseo también ilimitado.

De esta forma, en esta concepción del hombre desaparecen las relaciones entre personas como fundamento del orden social, puesto que ahora serán las relaciones entre el individuo y las cosas (que se convierten en objetos de deseo) las que organicen la sociabilidad humana ${ }^{17}$.

Asimismo, el individualismo acaba encarnando un prototipo de comportamiento representado por su homo economicus. La naturaleza de este constructo teórico será la búsqueda de su interés individual centrada en la posesión de bienes materiales en competencia con el resto de los individuos ${ }^{18}$. De esta forma, este enfoque individualista afirma que en «el origen de los servicios económicos que los hombres mutuamente se prestan está la inclinación al trueque, justificado por su deseo natural de obtener ganancias» (Lucas, 1994: 25) ${ }^{19}$. Por tanto, el utilitarismo del individualismo creado por el análisis económico establecía la competencia entre los seres humanos como el eje fundamental de organización de la sociedad, todo lo cual obedecía a un orden natural y, por tanto, irrebatible ${ }^{20}$ : sus resultados son siempre necesarios y buenos. Ahora bien, el despliegue libre de esta naturaleza humana tan sólo se puede realizar en el mercado como plasmación de las leyes naturales que deben regir las rela-

16 Como poseedor de una especie de «gen comercial» (Dalton, 1968: xv).

17 Las interacciones entre los individuos se objetifican, es decir, los individuos se consideran mutuamente como medios para la obtención de cosas y no como fines en sí mismos. Esta diferenciación está en la base de las nociones de «comunidad/asociación» de Tönnies (1992), de «solidaridad mecánica/orgánica» de Durkheim (1992) y en las de "comunación/socialización» de Weber (1986), e incluso en la noción de «fetichización de la mercancía» en Marx (1978).

18 De esta forma, la búsqueda de beneficio y ganancia se realiza a través del antagonismo de los contratantes (Polanyi, 1976c: 300).

19 «No es de la benevolencia del carnicero, del cervecero o del panadero que esperamos nuestro sustento, sino de la búsqueda de sus propios intereses. Apelamos no a su humanidad sino a su egoísmo y nunca le hablamos de nuestras necesidades, sino de sus ventajas» (Smith, 1982).

${ }^{20}$ Lo que Polanyi denomina solipsismo económico (ESH: 87-89). 
ciones sociales (Bilbao, 1996: 75) y que proceden de una evolución espontánea de las sociedades humanas.

El individualismo y su expresión en el homo economicus que actúa exclusivamente en búsqueda de una ilimitada adquisición de objetos de deseo supone la separación de lo económico de la totalidad social, la construcción de un dominio autónomo (Dumont, 1982: 17) autorregulado y basado en el móvil de ganancia como justificación del comportamiento de la vida cotidiana $(E S H$ : 66). Lo fundamental, dirá Polanyi, es que la esfera económica, el sustento del hombre, se desincrustará de la sociedad y subordinará a todas las instituciones de ésta, pasando a ser el mercado el organizador de las relaciones sociales entre los individuos (ESH: 84). En otras palabras, se sustantiviza el significado formal de lo económico en el que «el "hombre económico" era el hombre real y el sistema económico era realmente la sociedad $»^{21}$ (ESH: 85).

Lo que planteará la obra de Polanyi es la necesidad de explicar cómo surge y se construye esta estructura individualista de pensamiento y, sobre todo, cómo acaba construyendo una realidad en la que los individuos terminan adquiriendo sus comportamientos utilitaristas ${ }^{22}$. La premisa fundamental de Polanyi será que, frente a su pretendido carácter natural, el homo economicus no es más que resultado de un proceso cultural a explicar, es artificial, puesto que de nuevo la historia ofrece ejemplos de formas diferentes de organizar la sociedad a partir de concepciones alternativas del hombre opuestas al individualismo ${ }^{23}$.

${ }^{21}$ «Ese individuo somos nosotros mismos, no ha sobrevivido ninguna transformación radical: entronizamos la propiedad privada, escogimos ser individuos posesivos y productores, volvimos la espalda tanto a la totalidad social como a nuestro vecino" (Dumont, 1982: 135).

22 «Son sólo nuestras sociedades occidentales las que recientemente han transformado al hombre en un animal económico» (Mauss, citado en Dalton, 1968: xii).

${ }^{23}$ «La economía primitiva no se basaba en el egoísmo, ni en un instinto de intercambio, ni en el estímulo de la ganancia individual. Si el egoísmo es natural, las sociedades salvajes eran contranatura (unnatural)» (Polanyi, 1947: 112). Asimismo, se debe destacar que, en términos de racionalidad, el homo economicus del análisis económico acaba integrado en un mundo sumamente idealizado, en el que los individuos actúan con una total información y previsión, adoptando tan sólo decisiones económicas racionales para la maximización de sus fines, sin aparecer en este esquema teórico ningún tipo de limitación cultural; todo lo cual tiene poca relación con el sistema económico real y concreto, y con las posibilidades y situaciones en que los individuos actúan realmente (Kaplan, 1976: 217-218). La racionalidad como optimización aparece así como independiente de toda opinión en cualquier localización espacial y temporal (Mirowski, 1990). Para analizar esa complejidad real y teórica de las supuestas acciones racionales y las dificultades de un comportamiento humano perfectamente racional, Keynes (1943: cap. XII), Shackle (1976), Izquierdo (1996) y Mirowski (1996). Esta nueva concepción de las relaciones humanas encuentra su expresión formal más precisa y altamente elaborada en la ciencia económica y en una gran parte de sus investigaciones (Orlèan, 1991). 


\subsection{Sistemas axiológicos y estructuras de pensamiento alternativas: el holismo en las sociedades sin mercado}

Si la tendencia al trueque y a la obtención egoísta del máximo beneficio fuera natural, el homo economicus tendría que haber sido encontrado en épocas diferentes de la historia. Sin embargo, los estudios sobre historia y antropología económica del propio Polanyi pretenderán refutar el inmanentismo del individualismo a través de la recuperación de experiencias históricas en las que las instituciones, las relaciones y pautas de comportamiento en que la sociedad produce, distribuye y consume los bienes y servicios no tienen nada que ver con el individualismo utilitarista ni con el significado formal de lo económico (con el economizar).

Para Polanyi, frente al móvil de ganancia basado en la competencia entre los individuos, las instituciones económicas en las sociedades arcaicas se crean no sólo para la obtención del sustento, sino, por el contrario, también para mantener la solidaridad comunal, excluyendo así el antagonismo del beneficio basado en el egoísmo ${ }^{24}$. De esta forma, la vinculación de bienes no se basa en el cálculo utilitario, de beneficio y de pérdidas, sino que satisface necesidades emocionales y estéticas de un orden más elevado: la integración y reproducción social (Frazer, en Malinowski, 1986: 9-12). Asimismo, la organización de la vida económica no depende de interacciones entre individuos aislados en lucha por la maximización del sustento, sino que se garantiza éste para todos «excluyendo la motivación del beneficio económico individual en la producción e intercambio de bienes, que es resultado de comportamientos pautados por un sentimiento generalizado de desprendimiento y solidaridad ${ }^{25}$ (Lucas, 1994: 33): el destino económico individual respecto del sustento se identifica con el destino colectivo ${ }^{26}$.

Polanyi afirma que la economía humana y el sustento del hombre en estas otras sociedades históricas (que van desde la sociedad de Hammurabi y el reino de Dahomey a las civilizaciones americanas precolombinas, de la Grecia clásica

${ }^{24}$ Es decir, asegurar las relaciones pacíficas sobre el sustento (ESH: 135-136) basando los intercambios en fines no lucrativos.

${ }^{25}$ Este ejemplo está referido a las comunidades de las islas Trobriand, del Pacífico, que sirve para ilustrar una organización del sustento y de la sociedad de carácter holista y opuesto al homo economicus, rompiendo así con el mito del comportamiento utilitarista del «salvaje» primitivo recogido por el análisis económico (Malinowski, 1986).

${ }_{26}$ En el caso de los trobriandeños, «se produce así a través de todo el tejido social una vinculación permanente de alimentos que hace prácticamente imposible que ningún trobriandeño se sienta individualmente amenazado por el hambre» (Lucas, 1994: 28). "Ninguna comunidad que desee preservar la solidaridad entre sus miembros permite que se desarrolle una hostilidad en torno a la comida como sustento vital» (Polanyi, 1957c: 301); «lo que aparecía como comunismo en las sociedades primitivas, era el hecho de que el sistema económico y productivo estaba arreglado de tal modo que no amenazaba a ningún individuo con el hambre. Es lo que hacía a la sociedad primitiva más humana que a la del siglo XIX y al mismo tiempo menos económica» (Polanyi, 1947: 112; Polanyi, 1966). 
a las islas Trobriand...) no tenía su origen en el carácter ilimitado de deseos y necesidades del ser humano o en el fenómeno de la escasez, sino en otro tipo de instituciones no económicas (estatus, magia, vasallaje...) (Polanyi, 1976b: 109). En estas sociedades la situación económica está entrelazada con múltiples relaciones sociales diferentes (Polanyi, 1976b: 113), con lo que la esfera económica no es autónoma: sigue incrustada en la sociedad ${ }^{27}$.

Este enfoque que recoge la totalidad social (y que recordemos es el eje fundamental del análisis institucional polanyiano) puede ser denominado, siguiendo a Dumont (1982), como holismo, enfrentándose a las concepciones del individualismo al valorizar el orden social a partir de la conformidad de cada elemento a su papel en el conjunto social, o, lo que es lo mismo, subordinar las necesidades del individuo a la colectividad. En este orden primarían las relaciones entre sujetos y no entre individuos y cosas (Dumont, 1982: 11-17), todo ello con el objeto de mantener la cohesión de la sociedad (Polanyi, 1976b: 134$)^{28}$.

Polanyi ejemplificará este enfoque sobre la naturaleza del individuo y de sus relaciones sociales mediante la recuperación de la obra de Aristóteles y su modelización de una noción de individuo opuesta ontológicamente a la propia noción de homo economicus del individualismo. Frente a éste, el individuo aristotélico es un sujeto que para su sustento adquiere bienes limitados y en cuya actividad tiene en cuenta los deseos y necesidades de los demás, siendo por tanto un sujeto cuyos movimientos de adquisición están determinados por su relación con los demás, centrada en el mantenimiento de la integración social, no pretendiéndose una separación egoísta de lo que acontece al individuo de lo que sucede a la totalidad (Bilbao, 1996: 76-81): «la suficiencia no es el vivir solo, sino para los ciudadanos» (Aristóteles, 1989: Libro I, cap. 4). Por tanto, el comportamiento de este individuo no se rige por la competencia o el incentivo de ganancia individual, sino por la buena voluntad o la amistad (philia) respecto a los demás (Polanyi, 1976b: 126), puesto que todos forman parte de un destino colectivo común ${ }^{29}$, en el que el sustento se concibe como el recono-

${ }^{27}$ Los restos contemporáneos de estas sociedades han desaparecido bajo el formidable efecto de erosión, mutación o de destrucción radical consecuencia de la dominación del sistema capitalista (Godelier, en Polanyi, Arensberg y Pearson, 1976: 9): "Todo ha sido barrido por el choque con la civilización capitalista: organización social, cultura, modos de producción material, etc.» (Lucas, 1994: 35).

28 «La solidaridad de la tribu se cimenta en una organización de la economía que neutraliza los efectos destructivos del hombre y del deseo de la ganancia, explotando al máximo las fuerzas de un destino económico común» (ESH: 130). En el enfoque holista la sociedad no es reductible a una simple agregación estadística de los comportamientos individuales, sino que tiene una identidad específica que se sitúa por encima del individuo y otorga prioridad a fines colectivos, incluyendo fines que coartan los deseos individuales; la sociedad es una totalidad orgánica donde todo sujeto está unido a todo el mundo a través de una compleja red de relaciones (Orlèan, 1991).

${ }^{29}$ Una crítica a la visión de Polanyi sobre Aristóteles se encuentra en Godelier (Polanyi, Arensberg y Pearson, 1976: 25). 
cimiento de un derecho moral de pertenencia a una comunidad humana (Dalton, 1968: xiii). Por todo ello, Polanyi afirma que el carácter natural del deseo ilimitado es falso y que, por tanto, ha sido y podría ser posible organizar la sociedad a partir de otros valores sociales ${ }^{30}$.

Polanyi defiende entonces la posibilidad (demostrada históricamente) de construir la sociedad a partir de valores sociales diferentes. De hecho, pretende rastrear el movimiento ideológico que provocó la transición de una estructura de pensamiento holista al individualismo ${ }^{31}$ sobre el que se funda la economía de mercado, lo que implica reconocer que las ideas y valores son un aspecto fundamental de la vida social (Dumont, 1982: 13).

A partir de todo esto, su obra analizará cómo los valores ideológicos del individualismo y su concepción sobre la supuesta naturaleza humana basados en la ficción mercantil del análisis económico, junto a su falsa pulsión innata al beneficio, transformarán en un muy breve período de tiempo la esencia misma de la sociedad humana (ESH: 81). Lo fundamental será que esta estructura de pensamiento acabará endurecida en la realidad a través de enormes procesos de inversión material, ideológica y de conocimiento, y de amplias movilizaciones de todo tipo de recursos para construir las estructuras de apoyo

${ }^{30}$ Cabe destacar que para Aristóteles era necesario encauzar los deseos y acciones de los individuos por la Razón, entendida ésta como una norma social y de conocimiento que busca la cohesión social (Aristóteles, 1989: Libro I, cap. 3). Frente a esta perspectiva, la pasión que rige el deseo del individualismo se basa en una razón que no tiene ningún componente ético, estando tan sólo referida a una relación utilitarista entre medios y fines. Aristóteles rechazará así toda adquisición basada en la búsqueda del beneficio individual por atentar contra la integración social (Prieto, 1996: 27; Aristóteles, 1985).

31 Asimismo, ambas concepciones difieren en su consideración o construcción social del valor económico. La adquisición determinada de bienes en la sociedad holista no se basa en la búsqueda de ganancia, con lo que el intercambio se centra en el valor de uso de los bienes, que, por tanto, deben ser equivalentes en su valor para la satisfacción de necesidades (de ahí la noción de precios fijos administrados socialmente con base en la equivalencia); esto implica la necesidad de valorar objetivamente los elementos intercambiables en relación a un precio justo. Por el contrario, la adquisición indeterminada o ilimitada del individualismo, basado en el egoísmo y el deseo, se centra en un intercambio basado en el valor de cambio de los objetos, pero ese valor de cambio no puede ser establecido objetivamente para establecer sus equivalencias, sino que parte de la subjetividad del deseo de los individuos que buscan la obtención de un beneficio también subjetivo en su antagonismo, lo que queda reflejado en un precio fluctuante según la disparidad de valores que los individuos atribuyen a las mercancías. Por tanto, el comportamiento en la economía de mercado no es la cobertura de necesidades a través del intercambio de valores equivalentes (basado en la «amistad social» con los demás), sino la obtención de un beneficio subjetivo (o plusvalía de deseo) a través del antagonismo y la competencia con los demás (González León, 1996). Para analizar la historia de la teoría del valor del análisis económico desde una perspectiva hermenéutica sobre la teoría social del valor, Mirowski (1991). Por otro lado, desde una configuración social de carácter holista, el principio básico de organización social será la virtud, entendida como un comportamiento ético referido a satisfacer las expectativas sociales de los demás en el mantenimiento de la cohesión y armonía social. Por el contrario, el individualismo establece el comercio como elemento sobre el que construir la sociabilidad humana, en la que la virtud se sustituye por los intereses egoístas de satisfacción de deseos, que el individualismo supone tendrá como resultado no intencional la promoción del bien común (Pascual, 1996). 
que configurarán la institución del mercado y la estructura de pensamiento en que se fundamentaba.

En definitiva, frente a su supuesto carácter natural, espontáneo y evolutivo, Polanyi opondrá una visión de la economía de mercado como resultado de una violenta institucionalización deliberada y artificial basada en el poder y la coerción: «una organización económica extraordinariamente artificial» (Polanyi, 1989: 43$)^{32}$.

\section{LA INSTITUCIONALIZACIÓN DE LA ECONOMÍA \\ DE MERCADO: EL PROCESO DE CONSTRUCCIÓN SOCIAL DE LA SOCIEDAD DE MERCADO}

Polanyi analizará la construcción sociohistórica de la economía de mercado en lo que se considera su obra fundamental, La gran transformación, que supondrá la base del resto de sus obras posteriores. Como hemos visto, para este autor, la economía de mercado supone una forma de integración y una construcción del orden social característica de los dos últimos siglos y que supone una ruptura radical con el modo en que las anteriores sociedades históricas habían obtenido el sustento: «una civilización única en la historia» (LGT: 27).

El fundamento sobre el que se desplegarán los diversos procesos culturales, políticos y de inversión y movilización de todo tipo de recursos está basado en la estructura de pensamiento que hemos denominado individualismo y analizada anteriormente. Polanyi considera a esta visión antropológica sobre la naturaleza humana como una utopía que desencadenará inmensos procesos ideológicos, materiales y de conocimiento para acabar siendo instalada o moldeada en la realidad. Esta utopía individualista y liberal «será el principio organizador de una sociedad que se afanaba por crear un sistema de mercado" (LGT: 223) ${ }^{33}$.

La realización de la economía de mercado promovida por la utopía liberal se basará en organizar el sustento de la sociedad a partir del móvil individual de la ganancia frente al móvil de la subsistencia colectiva. La articulación del principio de lucro individual se realizará a través de la idea de un sistema de mercados autorregulados y gobernados exclusivamente por precios fluctuantes según la denominada «ley de la oferta y la demanda» (por el análisis económico y su significado formal de lo económico). Todo esto supondrá organizar las actividades diarias de los seres humanos a través de mercados basados en el beneficio, la competencia y los valores utilitaristas, es decir, toda la organización social queda subordinada al propósito de lucro, convirtiéndose así la ganancia económica en un fin absoluto (ESH: 62).

32 Esta referencia es La gran transformación; a partir de ahora será referida en el texto como $L G T$.

33 «Nociones nuevas sobre el hombre y la sociedad se hicieron corrientes y ganaron el estatus de axiomas» (Polanyi, 1947: 110). 
Estos mercados se autorregulan por la formación de precios libres, lo que supone acabar con las regulaciones institucionales que sobre ellos las formas de integración de otras sociedades habían establecido para la obtención del sustento y la reproducción de la sociedad. En la institución del mercado, todo lo que forma parte del sustento aparece como una mercancía para su venta y adquisición libre en el mercado, con lo que éste rige el destino de todos los componentes de la vida económica (y extraeconómica) (Prieto, 1996: 24).

De esta forma, las mercancías serán todo lo producido para el mercado (LGT: 128), pero éste también regulará otros elementos fundamentales para el sustento y la sociedad como el trabajo y la tierra, que originalmente no son mercancías puesto que no son producidas para el mercado, sino para la reproducción de los individuos y la sociedad. Sin embargo, el mercado autorregulador mercantilizará ambos factores: mercantilizará la humanidad y la naturaleza, subordinando así la sustancia de la sociedad a este nuevo orden de organización social (LGT: 123-128).

Por todo ello, es fundamental seguir el proceso de mercantilización forzada (Prieto, 1996: 28) del trabajo y de la tierra como origen de la propia economía de mercado. Respecto al trabajo, su mercantilización se referirá al fomento del hombre para el trabajo en el mercado a través de la destrucción de los vínculos sociales que anteriormente evitaban su integración y disposición en el mercado. De esta forma, a la socialización del impulso de la ganancia como fin último se añadió un impulso más ineludible: el incentivo de evitar el hambre. Para que el hambre obligara a los sujetos a integrarse en el mercado era necesario separarles de sus medios de subsistencia, o, lo que es lo mismo, forzarles a obtener su sustento sólo a través del propio mercado ${ }^{34}$. En este proceso se separará súbita y violentamente a grandes masas humanas de sus medios de subsistencia a través de la expropiación de la propiedad de sus tierras (y de las tierras comunales de sustento colectivo) (LGT: 353) ${ }^{35}$.

Tras esta expropiación, aquellos que se mantenían mediante el suelo que cultivaban necesitarán ganarse el sustento trabajando para otros ${ }^{36}$ (Gaudemar, 1989) y viéndose obligados a integrarse en el mercado para satisfacer sus necesidades (Marx, 1978: 907-908) ${ }^{37}$. Este movimiento establecerá como elemen-

${ }^{34}$ La construcción del mercado como forma de integración institucionalizada supuso, por tanto, acuñar prácticas forzadas de comportamiento en las personas como único medio para obtener el sustento, comportamientos que no son expresión de una supuesta naturaleza humana, sino un fenómeno cultural (Dalton, 1968: xxiii).

35 «La acumulación originaria es el proceso histórico de escisión entre productores y medios de producción, es decir, de la creación de una mano de obra liberada de los medios de producción, que será valorizada por los propietarios de capital a través de su adquisición» (Marx, 1978: 891-905).

36 «La población rural expropiada por la violencia, expoliada de sus tierras y reducida al vagabundeo, fue obligada a someterse, mediante una legislación grotesca y terrorista, y a fuerza de latigazos, hierros candentes y tormentos, a la disciplina que requería el sistema de trabajo asalariado" (Marx, 1978: 922).

${ }^{37}$ Al igual que Polanyi, Marx resalta el carácter excepcional de la sociedad de mercado 
tos de organización social el incentivo del hambre y del beneficio ${ }^{38}$. Asimismo, la mercantilización de la naturaleza supondría eliminar los límites a su explotación sin tener en cuenta su posible destrucción en relación a la producción de sustento (alimentos y materias primas) (LGT: 128-130) ${ }^{39}$.

La instauración de la institución del mercado supuso, por tanto, la transformación de la esencia de la sociedad humana a través de una ruptura violenta de las condiciones de integración social precedentes. Todo ello condujo a que la sociedad fuera gestionada en tanto que auxiliar del mercado puesto que todo quedará incluido en su funcionamiento (LGT: 104-111).

Ahora bien, como hemos visto al analizar las bases teóricas de las propuestas de Polanyi, la economía de mercado entendida como una forma de integración institucionalizada requiere el establecimiento de estructuras de apoyo sin las que no hubiera sido posible su constitución (legislaciones, instituciones, códigos, escuelas, metrologías y conocimientos... ${ }^{40}$ ). La inversión en formas y la movilización de recursos para la destrucción masiva y violenta de las bases tradicionales de la sociedad (LGT: 135), para la creación de un mercado autorregulado, requirió la participación del poder político del Estado para crear y mantener el experimento utópico del liberalismo; por todo ello, la institucionalización del laissez-faire tendrá un origen estatal para desarrollar en la realidad las teorías del individualismo liberal, lo que se conseguirá a través de un continuo intervencionismo de la autoridad central: en definitiva, los defensores del liberalismo recurren al Estado para crear y mantener el laissez-faire ${ }^{41}$.

Aparece así claramente no sólo el carácter artificial de la economía de mercado, sino su base política, es decir, su establecimiento a través de procesos políticos centrados en el uso del poder de forma violenta para la creación de las estructuras que permitieron organizar la sociedad y el sustento del hombre alrededor de la institución del mercado ${ }^{42}$. Por tanto, la economía de mercado y

(sociedad burguesa), así como destaca que el interés privado está socialmente determinado y sólo puede ser perseguido dentro de las condiciones que la sociedad establece y por los medios que la sociedad ofrece (Dumont, 1982: 200). Sin embargo, Polanyi rechazará el determinismo económico que el marxismo comparte con el análisis económico.

${ }^{38}$ El beneficio se conseguirá a través de la explotación de esa necesidad de evitar el hambre de la gran mayoría expropiada y ahora mercantilizada.

39 «La tierra como la mano de obra fueron a lo largo de un período dilatado parte integrante del tejido social y no podía disponerse arbitrariamente de ellos sin que éste se descompusiera» (Polanyi, 1976b: 122).

40 La construcción teórica de conocimiento supone una forma de movilizar, cambiar, combinar y escribir sobre la realidad (Latour, 1992).

41 Todo ello invalidaría así el carácter espontáneo y evolutivo del mercado, que fue realmente consecuencia de un constructivismo planificado para insertar el liberalismo como principio organizador de la sociedad (LGT: 232-233). «La ley misma se convierte en el vehículo del robo contra las tierras del pueblo» (Marx, 1978: 906). "El nacimiento del laissez-faire supuso un shock sobre las visiones del hombre civilizado de cuyos efectos aún no se ha recuperado" (Polanyi, 1947: 110).

42 «La expoliación de los bienes eclesiásticos, la enajenación fraudulenta de las tierras fiscales, el robo de la propiedad comunal, la transformación usurpatoria practicada con el terrorismo más 
su expresión formal en el análisis económico tienen su origen en la política y la lucha por el poder para la aplicación pragmática de sus postulados: de ahí que su artificialidad dé lugar a una economía política ${ }^{43}$.

Todos estos procesos históricos implican que «el homo economicus, lejos de ser el núcleo fundamental y originario de la naturaleza humana, fuera el resultado histórico de una violenta institucionalización" (Lucas, 1994: 34). Ahora bien, esta institucionalización requiere la socialización de prácticas en los sujetos de manera que acaben no sólo integrados en el mercado autorregulado, sino que se mantengan en él, lo que da lugar a la necesidad de un continuo y sostenido esfuerzo político de disciplinamiento y vigilancia para imponer su legitimación e interiorización (Prieto, 1996: 29) ${ }^{44}$.

Por tanto, Polanyi realiza una arqueología tanto de las bases axiológicas del individualismo como de sus prácticas en la realidad, con lo que se desvela la construcción de la economía de mercado como modelación en la realidad de esos valores que comenzarán a darle sentido. A este respecto, toda alternativa a la economía de mercado requiere, por tanto, una crítica teórica sobre la que fundamentar sus prácticas; así es como se puede considerar y entender la obra de Polanyi.

A través de La gran transformación comprobamos cómo la utopía liberal e individualista acaba por hacerse realidad, es decir, es una hipótesis que acabó cumpliéndose a sí misma mediante los procesos de institucionalización cultural y política que acabamos de recoger: «ninguna concepción errónea del pasado se reveló nunca como una mejor profecía sobre el futuro» (LGT: 84).

La institución del mercado a partir de la cual se organizará la economía dio lugar al desarrollo de una sociedad embutida en ese mecanismo, es decir, provocó el surgimiento de una sociedad de mercado (ESH: 81), que Polanyi ejemplificará empíricamente en la sociedad europea occidental del siglo XIX. El ideal de la utopía acabó creando realidad y acuñando el estilo de vida de los individuos mediante su socialización en una cultura completa, identificada en

despiadado de la propiedad feudal y clánica en propiedad privada moderna fueron otros tantos métodos idílicos de la acumulación originaria. Esos métodos conquistaron el campo para la agricultura capitalista, incorporaron el suelo al capital y crearon para la industria urbana la necesaria oferta de un proletariado enteramente libre» (Marx, 1978: 918). «En la historia real el gran papel lo desempeña la conquista, el sojuzgamiento, el homicidio motivado por el robo: en una palabra, la violencia» (Marx, 1978: 892). Fue, en definitiva, un período para construir y asegurar el poder y la verdad de los sistemas del individualismo y para reprimir a la oposición (Pearson, en ESH: 45).

43 "Tantos esfuerzos se requirieron para asistir al parto de las "leyes naturales eternas" que rigen el modo capitalista de producción, siendo la liberación de la fuerza de trabajo ese producto artificial de la historia moderna” (Marx, 1978: 950).

${ }_{44}$ Disciplinamiento y vigilancia que aparecen incluso en la obra de Mandeville y Hayek, lo que contradice su perspectiva espontaneísta sobre el orden social del mercado (Pascual, 1996). El sujeto individualista no es más que un constructo teórico de conocimiento científico que se aplica como tecnología social y política para adueñarse de la realidad social (González León, 1996: 20). 
la imagen del hombre y la sociedad del individualismo ${ }^{45}$. Frente a las otras formas de integración en que la esfera económica estaba incrustada en lo social, la nueva sociedad de mercado conllevará la autonomía de lo económico; sin embargo, esto no significa que la economía se separe de la sociedad, sino, por el contrario, que ésta y todas sus esferas acaban subsumidas en la lógica del mercado: la sociedad se mercantiliza.

La creación histórica de esta sociedad supondrá, para Polanyi, fomentar la aniquilación de la sustancia humana y la naturaleza de la sociedad (LGT: 26) a través de la destrucción del anterior tejido social. Todo ello provocó la dislocación catastrófica de la vida del pueblo, su pauperización y disciplinamiento violento, el desgarro de la sociedad: "permitir que el mercado dirija y decida la suerte de los seres humanos conduce a la destrucción de la sociedad» (LGT: 129). El cambio cultural en las formas de vida que supuso esta organización social desgajó al ser humano de sus raíces y de un entorno con sentido, desplazándole a nuevos espacios donde sólo podrá trabajar míseramente ${ }^{46}$ (LGT: 114) a través de la sanción física del hambre. La sociedad de mercado, y la revolución industrial que desencadenó, produjo la desintegración cultural de las víctimas, de sus instituciones sociales y de sus formas de integración ${ }^{47}$ (LGT: 260262). En definitiva, «el edificio de la economía clásica supuso el más formidable de los instrumentos conceptuales de destrucción» (LGT: 392).

Finalmente, Polanyi recoge la oposición social que el proceso de instauración de la sociedad de mercado provocó en el tejido social, es decir, un contramovimiento de protección de la sociedad frente al mercado (LGT: 215). Esto suponía el surgimiento de conjuntos de ideas o de estructuras de pensamiento alternativas al mundo del mercado autorregulado. Estas nuevas estructuras pretenderán durante las primeras décadas del siglo XX una nueva acción de autodefensa que impidiera el establecimiento del mercado a través de la intervención en su libre funcionamiento (LGT: 322).

Esto supone, por tanto, crear visiones sobre la sociedad y el ser humano que se referirían a posibles nuevas formas de integración que aseguraran la protección de la sociedad. Básicamente, estos procesos de autoprotección llevarán finalmente a la articulación de alternativas teóricas, pero sobre todo políticas, que intervendrán en la sociedad de mercado para mantener las exigencias de la integración social ${ }^{48}$. De nuevo, estructuras de pensamiento pusieron en marcha

45 «La significación cultural del proceso de desarrollo que ha experimentado la gran industria... ha transformado el rostro espiritual del género humano hasta casi no poder reconocerlo y lo seguirá transformando" (Weber, 1994: 73-74); todo desarrollo económico es, por tanto, un desarrollo cultural (Thompson, 1967: 97).

${ }^{46}$ La sociedad de mercado se convertirá en una «fábrica satánica».

47 Para Polanyi, los resultados asombrosos en términos de producción y movilización de recursos de la economía de mercado se consiguieron mediante grandes daños a las bases de la sociedad (LGT: 300).

${ }^{48}$ El fascismo y el socialismo supusieron fuerzas fundamentales en la transformación institucional que acabó con la economía de mercado del siglo XIX (LGT: 65). 
procesos políticos de inversión y movilización de recursos para reorganizar la sociedad, al igual que anteriormente había hecho la utopía liberal. Estas nuevas estructuras fueron fundamentalmente el keynesianismo y el New Deal, la revolución soviética, pero también el fascismo ${ }^{49}$. El establecimiento de estas nuevas políticas y de sus instituciones provocará que «la civilización del siglo XIX fuera destruida por las diversas medidas adoptadas por la sociedad para no verse aniquilada por la acción del mercado autorregulador ${ }^{50}$ » (LGT: 389). De nuevo, unos procesos basados en el pensamiento y el conocimiento para la acción política.

\section{UNA VISIÓN POLÍTICA DE POLANYI: \\ DE LA CRÍTICA EPISTEMOLÓGICA A LA ACCIÓN POLÍTICA}

Estos movimientos de defensa fueron finalmente articuladores de nuevas medidas políticas también de movilización de recursos y procesos que provocaron la transformación institucional de la sociedad de mercado, actuando y regulando sobre esta institución como forma de organizar la sociedad. Será fundamentalmente durante los años treinta de este siglo cuando se produzca la gran transformación, es decir, una nueva revolución de los valores que actuará contra las ideas sobre las que se construyó la propia sociedad de mercado. La capacidad de esas nuevas estructuras de pensamiento para la acción política llevará al fin de la ficción mercantil: «la civilización del siglo XIX se ha derrumbado» (LGT: 25). Su intervención política supuso, por tanto, una nueva forma de unir la sociedad (LGT: 329), una nueva forma de integración institucional del sustento del hombre.

Por tanto, la política recuperará su papel de constructor moral de la sociedad, que había perdido en la sociedad de mercado al quedar reducida a una administración de las cosas dentro de un mundo ordenado por las leyes del mercado (Bilbao, 1996: 75), que, recuérdese, son naturales: "las leyes del comercio son las leyes de la naturaleza y, por consiguiente, las leyes de Dios» (LGT: 195), con lo que la intervención política tan sólo requería aplicar y respetar esas leyes del mercado. Frente a esto, esas nuevas estructuras ideológicas concebirán el uso del poder político como una intervención para evitar los resultados de la aplicación de esas leyes; por ello, el poder político optará por la regulación de la vida económica para evitar la desintegración social.

Todo ello supondrá recuperar una visión sobre las relaciones humanas de

49 El fascismo supondrá una reforma de la economía de mercado, extirpando todas las instituciones democráticas y forzando procesos de resocialización por métodos científicos de tortura para mantener el mercado y evitar y reprimir las alternativas políticas a su funcionamiento, básicamente las del movimiento obrero (LGT: 371-379; Kalecki, 1969).

50 Será precisamente a los resultados de las políticas de estas estructuras de autoprotección de la sociedad a los que Polanyi denominará "gran transformación», y no a la constitución de la propia sociedad de mercado. 
carácter holista centrada en «el sacrificio de los intereses particulares al interés general» (Durkheim, 1992: 17). La reglamentación de la esfera económica evitará que el resto de las esferas sociales se subsuman a ella (Durkheim, 1987: 263).

Como consecuencia de la llegada al poder de estas estructuras de pensamiento se producirán procesos de creación de nuevas instituciones para la producción, distribución y consumo del sustento. Estas formas de integración o de regulación social se centrarán en la limitación o supresión de la economía de mercado o, en otros términos, en la desmercantilización de las relaciones sociales. Su plasmación práctica o pragmática irá desde el derecho social y del trabajo al Estado del Bienestar a través del keynesianismo, y a los planes quinquenales de las estructuras políticas con origen en la revolución soviética, cuyo modo de producción burocrático sin mercado constituirá una forma de integración de la sociedad alternativa no sólo a la sociedad de mercado, sino a la del propio keynesianismo ${ }^{51}$. En ambas formas de integración reaparecerán la

${ }^{51}$ La obra de Keynes ha sido siempre analizada básicamente desde su contribución teórica y crítica al análisis económico. Sin embargo, es interesante enfocarla a partir de las reflexiones políticas sobre las que se fundamenta. Keynes muestra con su teoría económica los efectos negativos del mercado al rechazar la supuesta optimización en la utilización de todos los recursos productivos, afirmando que se puede llegar al equilibrio con subutilización de esos recursos. Para superar estos efectos negativos (el desempleo y la concentración de la renta) propondrá la necesidad del intervencionismo estatal para mantener la integración social mediante la incorporación de aquellos que quedaban fuera del funcionamiento del mercado. Keynes se sitúa así política y teóricamente en contra de los fundamentos del laissez-faire, rechazando éstos al considerarlos basados en principios metafísisicos que no son ciertos: «No es verdad que los individuos tengan una libertad natural sancionada por la costumbre en sus actividades económicas. No existe un convenio que confiera derechos perpetuos sobre lo que Tienen o sobre lo que Adquieren... no siempre coinciden el interés privado y el social... No es una deducción correcta de los principios de la economía que el interés propio ilustrado produzca siempre el interés público... La experiencia no demuestra que los individuos, cuando forman una unidad social, son siempre menos clarividentes que cuando actúan por separado" (Keynes, 1988: 290; cursiva de Keynes). Lo interesante es que Keynes reconoce que la base darwinista del laissez-faire se difundió al ser coherente con las necesidades del mundo de los negocios, iniciándose un amplio proceso de socialización que llevó a la educación de varias generaciones en sus principios: «El dogma se había apropiado de la máquina educativa; había llegado a ser una máxima para copiar. La filosofía política, que los siglos XVII y XVIII habían forjado para derribar reyes y prelados, se había convertido en leche para bebés y había entrado en el cuarto de los niños» (Keynes, 1988: 283). La obra keynesiana retoma la incrustación de la economía en la sociedad a través de su intervención política con el fin de mantener la integración de la sociedad. Su liberalismo social (frente al individualismo liberal) se centra en defender la libertad de los individuos, pero enmarcando sus acciones en el mantenimiento de la cohesión social a través de un régimen que controle y dirija las fuerzas económicas en «interés de la justicia social y la estabilidad social» (Keynes, 1988: 307), todo ello combinado con la eficiencia económica: «Si nos preocupa el bienestar de las jirafas, no debemos pasar por alto los sufrimientos de los cuellos más cortos que están muertos de hambre, o las dulces hojas que caen al suelo y son pisoteadas en la lucha, o el hartazgo de los que tienen el cuello largo, o el mal aspecto de ansiedad o voracidad agresiva que nubla los pacíficos rostros del rebaño" (Keynes, 1988: 287-288). Keynes pretenderá combinar la eficiencia capitalista en la producción con la integración social de sus miembros a través de la intervención en la institución del mercado: «Por mi parte, pienso que el capitalismo, dirigido con sensatez, puede probablemente hacerse 
redistribución y la reciprocidad como elementos institucionalizados de regulación social que establecerían de nuevo prácticas socializadas en el comportamiento de los sujetos.

La crítica epistemológica a la que Polanyi somete al análisis económico, y a los fundamentos ideológicos de la economía de mercado a través de los conceptos de su análisis institucional, cobra únicamente sentido desde una perspectiva política, es decir, como base para la acción transformadora de la realidad; en este caso, como alternativa teórica y política a la sociedad de mercado. Por tanto, la acción política requiere una crítica teórica: «el sentido de recuperar la preeminencia de la sociedad y de la política sobre la economía ha de pasar necesariamente por la crítica de la ciencia económica como tal» (Prieto, 1996: 32). Por todo ello, «el significado profundo y el tema unificador de su obra está en la esfera de la filosofía social y política» (Pearson, en ESH: 52).

Como se señalaba en la presentación, tan sólo dentro de este marco de intencionalidad política, Polanyi creerá pertinente realizar un inmenso esfuerzo para rastrear los orígenes de la economía formal convertida en sociedad de mercado. Su esfuerzo pretende contribuir a la resolución de los problemas básicos a que se enfrenta la humanidad contemporánea y cuyos ejes fundamentales sitúa en las posibilidades libertad/centralización e iniciativa/planificación (ESH: 57), que, como vemos, siguen siendo los elementos que impregnan el debate político y social en la actualidad, más de tres décadas después de la muerte de Polanyi (1964). Para éste, su obra tiene un objetivo: «ensanchar nuestra libertad de modificaciones creativas y por ende mejorar nuestras posibilidades de supervivencia» (ESH: 59), así como cambiar el eje económico a uno moral y político (ESH: 61).

A través de su reflexión teórica y empírica pretenderá impulsar el cambio deliberado de las instituciones humanas para restablecer los ideales de la justicia, la ley y la libertad (ESH: 71) mediante la recuperación de una cultura política que permita establecer fines al margen de la economía de mercado y su administrativismo de las cosas, lo que conlleva recuperar el papel de las instituciones políticas en el establecimiento de esos fines ${ }^{52}$, los cuales deben pretender

más eficiente, para alcanzar fines económicos, que cualquier sistema alternativo a la vista, pero que en sí mismo es en muchos sentidos extremadamente cuestionable. Nuestro problema es construir una organización social que sea lo más eficiente posible sin contrariar nuestra idea de un modo de vida satisfactorio" (Keynes, 1988: 296). Por último, es necesario recordar que Keynes desarrolló su obra en los momentos en que se consolidaba un modelo político alternativo de construcción de la sociedad, la economía y, por tanto, el sustento del hombre: la economía y sociedad soviética. Frente a esta alternativa, Keynes planteará sus teorías, que abogan por el mantenimiento del capitalismo pero a través del cambio en sus valores de construcción y organización.

52 No es más que orientar de forma alternativa el proceso político que instauró la economía de mercado: el solipsismo del análisis económico ocultó y olvidó el papel que el Estado y el poder tuvieron en la construcción de la sociedad de mercado, limitando y evitando así opciones ideológicas alternativas. 
que la tecnología industrial para la obtención de sustento sirva a las necesidades de la comunidad humana (Dalton, 1968: xv).

A partir de su obra, Polanyi planteará una serie de principios de acción política que permitan dar respuesta a los referidos problemas de la humanidad a partir de una nueva estructura de pensamiento que supere «nuestra obsoleta mentalidad de mercado" ${ }^{53}$ (Polanyi, 1947: 109). Tan sólo "la supresión de la economía de mercado acabará con la explotación de unos sobre otros, con las ganancias sin servicio a la comunidad, con un uso de las tecnologías que no produce beneficios públicos y con la obtención de beneficios mediante las calamidades de los demás» (Polanyi, 1947: 116). Solicitará Polanyi, por tanto, una vuelta a una economía socialmente incrustada que no empobrezca a los individuos, incluso "al precio de una sociedad tecnológicamente menos eficiente» (Polanyi, 1947: 116), todo lo cual requiere un poder central organizado que regule la economía de mercado.

Ahora bien, el propio Polanyi rechaza algo que sus críticos le reprochan, su supuesto romanticismo respecto al altruismo y la solidaridad de unos idealizados "primitivos" (Kaplan, 1976: 120), afirmando que una vuelta a los ideales del pasado no puede enseñar el camino (Polanyi, 1947: 109), ni tampoco una huida hacia una nueva era neolítica $(E S H: 64)^{54}$. El camino tan sólo podrá encontrarse reconociendo que la economía de mercado ha venido para quedarse de manera irreversible ( $E S H:$ 65), pero buscando formas alternativas para su organización a través de un cambio dirigido para la conservación del bienestar colectivo (LGT: 72-74).

Frente a los que suponen ese romanticismo antimercado en Polanyi, éste vuelve a demostrar la complejidad de su análisis al afirmar que la sociedad de mercado, sin embargo, posee libertades que son positivas ${ }^{55}$, como la libertad de pensamiento, de conciencia, de reunión, etc. (Polanyi, 1947: 116), pero enfatizando que las garantías institucionales de la libertad personal son compatibles con cualquier sistema económico: «creemos firmemente en el progreso y las libertades, pero también en alcanzar un nivel de integración humana que com-

53 En la actualidad asistimos a la recuperación hegemónica de esa mentalidad de mercado como principio para organizar la sociedad, con lo que aquello que aparecía como obsoleto en la época de Polanyi (período básicamente keynesiano o de economía planificada en el socialismo real) está volviendo a ser la estructura de pensamiento dominante (proceso cultural que puede ser un buen objeto de investigación a partir del esquema teórico polanyiano).

54 «Sugerir que la economía y la sociedad primitivas proveían seguridad material y psicológica es arriesgarse a ser acusado de nostalgia —el equivalente moderno de la creencia en el buen salvaje- Frecuentemente en las sociedades primitivas, la vida material es pobre y la vida física es desagradable y corta: la pobreza, la enfermedad, la muerte y el dolor son elementos habituales. Pero la vida social tiene sentido y las relaciones sociales son inmediatas y cruciales para el bienestar de una persona» (Dalton, 1968: xiii).

55 Esta ambivalencia respecto a la positividad de las libertades del individualismo liberal aparece también en Simmel, el cual destaca que la modernidad (relacionada con el desarrollo de la economía de mercado) ha permitido la liberación de los individuos de las relaciones sociales comunitarias que coartaban su comportamiento (Simmel, 1977). 
prenda la economía sin dejarse absorber por ella» (Polanyi, Arensberg y Pearson, 1976: 48). Estas libertades sólo podrán ser realmente socializadas para conseguir más libertad para todos a través de la regulación social de la economía (LGT: 405).

Finalmente, Polanyi planteará que «en una verdaderamente democrática sociedad el problema de la industria se resolvería mediante la intervención de los productores y los consumidores, lo que mantendría su libertad" (Polanyi, 1947: 117). Todo ello requiere una nueva forma, o una nueva estructura de pensamiento, de ver a los seres humanos y a la sociedad, distinta de la heredada por la economía del mercado.

\section{CONCLUSIÓN}

La estructura de pensamiento recogida en la obra de Karl Polanyi es una de las aportaciones que permitirá reflexionar sobre la sociedad actual a través de la articulación de una pertinente, exhaustiva y elaborada crítica epistemológica que sólo podrá tener sentido como una crítica política con efectos en la realidad y con una inversión en formas de reconstruir el orden social ${ }^{56}$. En definitiva, un pensamiento para la acción transformadora que es sumamente relevante en una situación en que los principios del individualismo que fundamentan la economía de mercado vuelven a convertirse en pensamiento y acción política hegemónica creadora de realidad. Polanyi desarrollará todo un enfoque teórico y metodológico institucionalista que permite comprender el proceso de construcción de la economía de mercado, cuyos principios de articulación siempre aparecen como evidentes y sin necesidad de ser explicados. El desvelamiento del origen y de los fundamentos de esos principios permitirá a Polanyi, a través de sus elaboraciones conceptuales (economía formal/sustantiva, formas de integración, holismo...), orientar su crítica al pensamiento económico hacia una perspectiva política centrada en afirmar la necesidad de rechazar y transformar la economía de mercado a través de la construcción de un orden social basado en principios diferentes y opuestos a aquellos sobre los que ésta se sustenta.

Por tanto, el trabajo intelectual de Polanyi sólo adquiere sentido desde una perspectiva política, desde un enfoque centrado en la elaboración de un pensamiento para la acción.

56 Es muy esclarecedora la introducción biográfica que realiza Ilana Polanyi en ESH respecto a la faceta política de Karl Polanyi: «Nunca he sido un político, no tenía talento para ello, ni siquiera interés»; "Puse todo mi poder y mi fuerza en un idealismo rígido, y sus altos vuelos se han hundido en el vacío" (ESH: 29-30). 


\section{BIBLIOGRAFÍA}

Alonso, L. E., y Callejo, J. (1994): «Consumo e individualismo metodológico: una perspectiva crítica", Política y Sociedad, n. ${ }^{\circ} 16$, pp. 111-134.

Aristóteles (1985): La Política, Madrid, Espasa-Calpe.

- (1989): Ética a Nicómaco, Madrid, Centro de Estudios Constitucionales.

BilbaO, A. (1996): "Aristóteles y Smith: la política y la ciencia", Politica y Sociedad, n. ${ }^{\circ}$ 16, pp. 73-87.

Dalton, G. (ed.) (1968): Primitive, archaic and modern economies. Essays of Karl Polanyi, Boston, Beacon Press.

Dumont, L. (1982): Homo aequalis, Madrid, Taurus.

DurKHEIM, E. (1987): El suicidio, Madrid, Akal.

- (1992): La división del trabajo social, Madrid, Akal.

ELIAS, N. (1982): La sociedad cortesana, México, FCE.

FouCAult, M. (1972): Las palabras y las cosas, México, FCE.

GARCÍA-Pelayo, M. (1992): Las transformaciones del Estado contemporáneo, Madrid, Alianza.

Gaudemar, J. P. (1989): La movilización general, Madrid, La Piqueta.

Godelier, M. (1976): Antropología y economia, Barcelona, Anagrama.

GonZÁlez León, R. (1996): «Dinero y acción racional según L. von Mises», Politica y Sociedad, n. ${ }^{\circ} 16$, pp. $9-21$.

Goody, J. (1990): La lógica de la escritura y la organización de la sociedad, Madrid, Alianza.

HAYEK, F. (1994): «Información y sociedad mercantil», en L. PUTTERMAN, La naturaleza económica de la empresa, Madrid, Alianza, pp. 85-92.

- (1995): Las tendencias del pensamiento económico: ensayos sobre economistas e historia económi$c a$, Madrid, Unión Editorial.

IzQUierdo, A. J. (1996): «Equilibrio económico y racionalidad maquínica», Política y Sociedad, n. ${ }^{\circ} 16$, pp. 89-111.

KALECKI, M. (1969): Ensayos económicos sobre la dinámica de la economía capitalista, México, FCE.

KAPLAN, D. (1976): «La controversia formalistas-sustantivistas de la antropología económica», en M. Godelier, (1976: 208-232).

Keynes, J. M. (1943): Teoría general de la ocupación, el interés y el dinero, México, FCE.

- (1988): Ensayos de persuasión, Barcelona, Crítica.

LAHERA, A. (1998): «Fábrica y comunidad. Transformación del trabajo e interdisciplinariedad en las Ciencias Sociales del Trabajo", Sociología del Trabajo, n. ${ }^{\circ} 33$, pp. 71-103.

LATOUR, B. (1992): Ciencia en acción, Barcelona, Labor.

LÉVI-STRAuss, C. (1995): Antropología estructural, Barcelona, Paidós.

LUCAS, A. (1994): "Sociedad de consumo o sociedad de mercado: el caso de las comunidades kula", Politica y Sociedad, n. ${ }^{\circ} 16$, pp. 25-86.

MalinowsKi, B. (1986): Los argonautas del Pacífico occidental, Barcelona, Planeta-Agostini.

MARX, K. (1978): El capital, Madrid, Siglo XXI.

Mauss, M. (1979): Antropología y sociología, Madrid, Tecnos.

Mirowski, P. (1990): "The rhetoric of modern economics», History of the Human Sciences, 3 (2), pp. 243-257.

- (1991): "Learning the meaning of a dollar: conservation principles and the social theory of value in economic theory», Social Research, 57 (3), pp. 689-717.

- (1996): “¿Sueñan las máquinas?: de los agentes económicos como cyborgs», Política y Sociedad, n. ${ }^{\circ} 16$, pp. 113-131.

MOYA, C. (1982): Sociólogos y sociología, Madrid, Siglo XXI.

OrlèAn, A. (1991): "The origin of money», en J. P. DUPUY y F. J. VARELA, Understanding origins, La Haya, Kuwler, pp. 1113-143.

Pascual, E. (1996): «Bernard de Mandeville: la legitimación de la fantasía», Politica y Sociedad, n. ${ }^{\circ} 16$, pp. 35-55. 
POlanYI, K. (1947): "Our obsolete market mentality», Commentary, n. o 3, pp. 109-117.

- (1966): Dahomey and the slave trade, Seattle, University of Washington Press.

- (1968a): «The semiotics of money-uses», en Dalton (1968: 175-203).

- (1968b): "On the comparative treatment of economic institutions in antiquity with illustrations from Athens, Mycenae, and Alalakh», en Dalton (1968: 306-334).

- (1976a): «Intercambio sin mercado en tiempos de Hammurabi», en K. Polanyi, C. Arensberg y H. Pearson (1976: 61-75).

- (1976b): "Aristóteles descubre la economía», en K. Polanyi, C. Arensberg y H. Pearson (1976: pp. 111-141).

- (1976c): "La economía como actividad institucionalizada», en K. Polanyi, C. Arensberg y H. Pearson (1976: 289-316).

- (1989): La gran transformación, Madrid, La Piqueta.

- (1994): El sustento del hombre, Barcelona, Mondadori.

Polanyi, K.; Arensberg, C., y Pearson, H. (1976): Comercio y mercado en los imperios antiguos, Barcelona, Labor.

Prieto, C. (1996): «Karl Polanyi: crítica del mercado, crítica de la economía», Política y Sociedad, n. ${ }^{\circ} 16$, pp. 23-34.

SCHOPEnhauer, A. (1993): Los dos problemas fundamentales de la ética, Madrid, Siglo XXI.

SHACKLE, G. L. (1976): Epistémica y economía, México, FCE.

Simmel, G. (1977): La filosofía del dinero, Madrid, Instituto de Estudios Políticos.

SMith, A. (1982): La riqueza de las naciones, México, FCE.

Thompson, E. P. (1967): "Time, work discipline and industrial capitalism», Past and Present, n. ${ }^{\circ} 38$.

TÖNnIES, F. (1992): Comunidad y asociación, Barcelona, Península.

Weber, M. (1986): Economía y sociedad, México, FCE.

- (1994): Sociología del trabajo industrial, Madrid, Trotta.

\begin{abstract}
Karl Polanyi's work provides one of the most exciting perspectives for tackling economic phenomena. Polanyi bases his epistemological and ontological review of the foundations of classic and neo-classic economic thought on the alternative provided by his institutional analysis, which is geared to embedding economic acts in the cultural, political and social womb in which they are conceived, which means that the economy is historically moulded by the social whole in which it is rooted. Thereafter, the historical construction of the market economy is presented as an immense and violent artificial social process, which did not spring from supposed aspects of human nature, but from an ideological, axiological and political ideology which radically differed from the previous ways in which human groups had organised and integrated material resources and their lifeblood. His theoretic criticism of the market economy as a force which splits human essence from society necessarily implies a political action which is capable of transforming and regulating the market, articulating its reflections as thought for action.
\end{abstract}

